\title{
Intention to complain in consumer who receives candies as change
}

\author{
Ilham Awaluddin \\ Department of Psychology \\ Faculty of Medicine \\ Hasanuddin Unversity \\ Indonesia \\ awal.ilham04@gmail.com
}

\author{
Muhammad Tamar \\ Department of Psychology \\ Faculty of Medicine \\ Hasanuddin Unversity \\ Indonesia
}

\author{
Elvita Bellani \\ Department of Psychology \\ Faculty of Medicine \\ Hasanuddin Unversity \\ Indonesia
}

\begin{abstract}
There is an absurd phenomenon in Indonesia where change that should be given to consumer is replaced to candies. This behavior violates government regulation regarding consumer rights. However, only some of costumers complain of this situation, while others do not. This situation raise question of why costumers complain while others don't. Behavior to address a complain can be investigated through intention to complain. Therefore, this study aims to examine description of consumer intention to make complaints based on predictor factors of intention: attitude toward behavior; subjective norm; and perceived behavioral control. This research employed quantitative approach with correlational design. There were $\mathbf{3 5 0}$ undergraduate students of Hasanuddin University participated in this study. Data analysis technique used in this study was Kendall's Tau correlation test.
\end{abstract}

The results of this study shows that there are $41.71 \%$ of costumers with low intention to complain, followed by $24.29 \%$ with moderate intention and $34 \%$ of costumers with high intention. The results of this study also show that all predictors of intention are significantly correlated with intention

Keywords-Intention; Theory of Planned Behavior; Complain Behaviour

\section{INTRODUCTION}

Lately, there are situations where after purchase, change that should be received by customer are not given by merchant, but are replaced with candies. This situation is violating the law and regulation because it is against costumer rights. However, not all costumers complain to the merchant regarding this situation.

According to Fairness Theory, when consumer's rights are not met, consumer will perceive this condition as unfairness [1]. Accordingly, perception of unfairness is occur when a person experiences an unpleasant experience (negative) even if he/she does not do anything negative (which makes her/him deserve of such negative experience). In this context, negative experience is experience of having their change replace with candies. In addition, being treated unfair will cause a moral outrage which will induce perception of unfairness.

Perceived unfairness will result in dissatisfaction, [2] and dissatisfaction will be the antecedent of complaint behavior [3]. This is in line with other studies which also found that consumer perception of unfairness will affect the complaint behavior [4] [5]. Therefore, ideally, consumer should make a complain when their change is replace with candies.

However, most of consumer do not complain when encountered with this situation. Most of the time consumer only just stand still and accept the candies given. Moreover, according to pilot interview, they are not angry with the situation. This is in contrast to what theory of fairness and previous research predict about complain behavior. Arguably, there are other aspect influence complain behavior rather than perception of unfairness and consumer dissatisfaction.

According to Theory of Planned Behaviour, intention is the main predictor of behavior. Accordingly, Intention is influenced by three factors: attitude toward behavior, subjective norm, and perceived behavioral control. If prevalence of these three factors is low, it will result in low intention to perform the behavior. Predictive ability of these three factors to behavior intention and behavior has been proven empirically. For instance, Bautabi, et.al. propose that attitude toward behavior, subjective norms, and perceived behavioral control influence intention to complain after purchasing defective product [6]. Other study by Lin, et.al shows that attitude toward behavior, subjective norms, and perceived behavioral control predict dishonest behavior of employees [7]. Arguably, when being treated unfair, these three determinant factors are the main determinants of complaint behavior.

This present study aims to examine consumer intention to complain after receiving candies as opposed to change they 
deserve. Correlation between attitude toward behavior, subjective norm and perceived behavioral to intention will be examined to explain intention to complain.

\section{LITERATURE REVIEW}

\section{A. Theory of Planned Behavior}

Theory of Planned Behavior is developed by Ajzen [8] as a refinement of the previous theory of reasoned action (TRA) proposed by Fishbein and Ajzen [9]. The main focus of the TPB is the same as the TRA which is intention or the tendency of a person to perform certain behavior. Intention is considered to be the motivational factors that influence behavior and become a major predictor of behavior. Intention is an indication of how hard a person willing to try and how much effort that person will be willing to spend to perform a certain behavior.

TRA suggests that there are two factors determined intention, which are attitude toward behavior and subjective norm [10]. Attitude refers to positive or negative evaluation regarding certain behavior. Subjective norm refers to a person perception regarding social pressure to or not to perform certain action [10]. However, Ajzen argues that TRA is not able to explain behavior of which not under the person control. As a consequence, Ajzen adds one factor which is perceived behavioral control and refine its theory to Theory of Planned Behavior. Perceived control behavior refers to a person perception about to what extend he/she has control over particular behavior. This factor explains a person perception of ease or difficulty to perform certain action. It is assumed that such perception is a result of previous experience and anticipated obstacles. Perceived control behavior, along with attitude toward behavior and subjective norm predict intention to perform certain action [8].

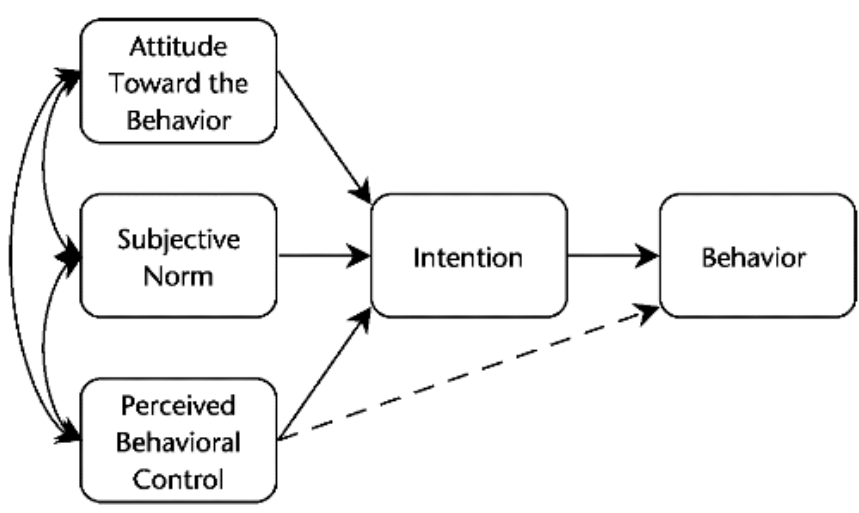

Fig 1. Theory of Planned Behavior

According to Fig. 1 [8], intention (and followed by behavior) is determined by attitude toward behavior, subjective norm and perceived control behavior. However, as can be seen for Fig. 1, perceived behavioral control has direct relation to behavior. Perceived control behavior is described to have direct effect because it is regarded as partial substitution of control, although this is not necessary appear in all behavior [8].

\section{B. Predicitons of Intention}

According to Theory of Planned Behavior [8], Intention is predicted by attitude toward behavior, subjective norm, and perceived behavioral control. Each of this predictor has its own antecedent which are described as followed:

- Attitude Toward Behavior

Attitude toward behavior is determined by combination of behavioral belief and outcome evaluation. To form a positive attitude toward behavior, a person should have a behavioral belief that performing intended behavior would result in positive outcome. Additionally, the person should perceive occurrence of positive outcome is desirable.

- Subjective Norm

Subjective norm is determined by normative belief and motivation to comply. Normative belief refers to what a person thinks regarding his social referent expectation to perform or not to perform the intended behavior. Motivation to comply refers to what extend the person wants to comply or not to comply with such expectation. To form a subjective norm, a person perception regarding social referent expectation must be combined with motivation to comply with such expectation.

\section{- Perceive Behavioral Control}

Perceive behavioral control is determined by control belief and perceived power control. Control belief refers to perception of facilitating factors or inhibiting factors to perform certain behavior. Perceived power control refers to perceived presence of facilitating or inhibiting factor in performing such action.

Relation between determinant factors (attitude toward behavior, subjective norm, and perceived behavioral control) has been clearly explain by Theory of Planned Behavior. Accordingly, attitude toward behavior along with subjective norm and perceived behavioral control predict intention and intention is main predictor of behavior [8]

Many studies using Theory of Planned Behavior have been conducted. To name but a few, studies by Ajzen shows that attitude toward behavior, subjective norm and perceived behavioral control predict intention in food consumption [8]. Similarly, a study by Bautabi shows that attitude toward behavior, subjective norm and perceived behavioral control influence intention to complain in financial situation [6]. Supporting this view, Mukhtiar et. al examine intention to complain about service failure propose that attitude toward 
behavior and perceived behavioral control are main determinant in influencing intention [11]. Adopting a similar position, Cheng and Chen suggest that consumer intention to complain in online and offline purchasing are predicted by attitude toward behavior, subjective norm and perceived behavioral control [12].

\section{METHOD}

\section{A. Participants}

There were 350 students of Hasanudin University aged 18-25-year-old participated in this study. Participants were recruited using incidental sampling technique. This sampling method was chosen because the exact number of population, which is the number of student who have ever received candies as change is unknown.

\section{B. Procedures}

Data collection was performed by distributing on line questionnaires and paper-based questionnaires. Prior to filling the questionnaire, prospective participants were given explanation about this study. Should they agree to participate, participants were asked to sign the informed consent.

\section{Measures}

Instrument to measure intention and its determinant factors was constructed by investigator. In construction the instrument, face validity, content validity and construct validity by confirmatory factor analysis were examined. There were 33 items invalid items and were deleted from 70 original items. Reliability analysis were measured by Cronbach's Alpha showed reliability coefficient of .752 .

\section{RESULT}

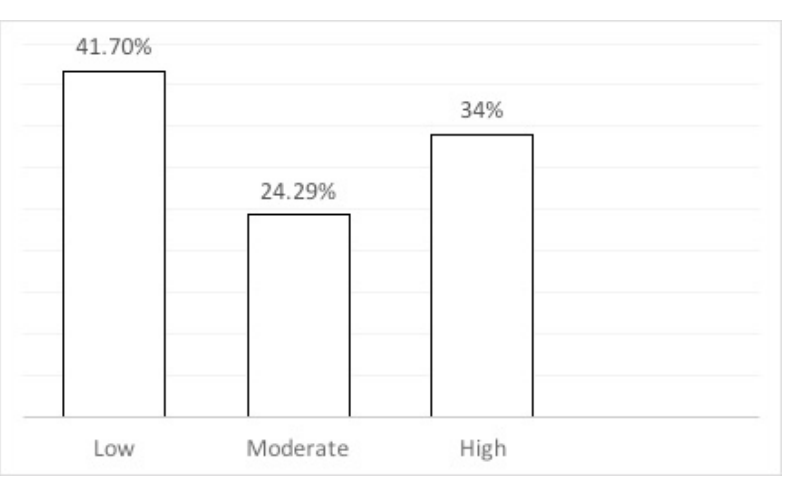

Fig. 2 Intention Distribution

As can be seen from Fig.2, most participants have low intention to complain (41.7\%), followed by high intention to complain (34\%) and moderate intention to complain $(24.29 \%)$
TABLE I. KENDALL'S TAU CORRELATION COEFFICIENT

\begin{tabular}{|l|c|c|}
\hline \multirow{2}{*}{ Predictors } & \multicolumn{2}{c|}{ Intention } \\
\cline { 2 - 3 } & $r t$ & Sig. \\
\hline Attitude Toward Behaviour & .646 & .000 \\
\hline Subjective Norm & .267 & .000 \\
\hline Perceived Behavioural Control & .490 & .000 \\
\hline
\end{tabular}

Table 1 displays correlation coefficient of attitude toward behaviour, subjective norm and perceived behavioural control toward intention. As can be seen, all determinant factors show significant positive correlation. However, the strength of correlation is differed where attitude toward behaviour shows the strongest correlation $(r t=.646, \hat{p}<.05)$, followed by perceived behavioural control $(r t=.267, \hat{p}<.05)$, and lastly, subjective norm $(r t=.490, \hat{p}<.05)$

\section{DISCUSSION}

This present study aims to investigate intention to complain in consumer who receive candies as change. Specifically, we aims to examine the correlation between determinant factors: attitude toward behaviour; subjective norm; perceived behavioural control; and intention to complain. The result of this study shows most participants $(41.7 \%)$, has a low intention to complain followed high intention to complain (34\%) and moderate intention to complain (24.29\%). This study also reveals that all determinant factors are significantly correlated to intention with varied strength of correlation. It is found that there are significant positif correlation between attitude toward behaviour and intention, $r t=.646, \hat{p}<.05$ subjective norm and intention, $r t=.267, \hat{p}<.05$ and perceived behavioural control, and intention, $r t=.490, \hat{p}<.05$. According to these coeffisient correlations, it can be concluded that only two determinant factors that have strong correlation to intention, which are, attitude toward behaviour and perceived behavioural control. Subjective norm in contrast, only has low correlation to intention.

Significant correlations between determinant factors and intention obtain in this study confirm that attitude toward behaviour, subjective norm and perceived behavioural control are positively correlated to intention. Therefore, it can be concluded that these determinant factors are predictor of intention. Variation in coefficient correlation found in this study also confirm what Azjen propose, that predictive ability may differ among factors, depending on behaviour being assessed [8] 
In this study, the strongest correaltion is found in the relation between attitude toward behaviour and intention, $r t=$ .646. This result indicates that a person perception about outcomes that will occure as a consequence of performing certain action is correlated with intention. In other words, when a person perceive that complaining will result in positive outcome and evaluate that the positive outcome is important to him, a person will more likely to complain, and vice versa. Comparing with data in Figure 1, which shows that most people have low intention to complain, it can be assumed that most subject perceive complain will result in negative outcomes.

The current study found that most participants (52.9\%) belief that minimarket or seller will never stop to give them and other consumers candies as a change even if consumer complain about it. This result support the previous study that suggests that perceive probability about the success of complaint will influence intention to complain [13]. When consumer perceive that their complaint will be accepted by the store they are more likely to have an intention to complain. This result also consistent with previous study that shows consumers who have a positive attitude toward complain behaviour have a higher tendency to complain [14].

To gain a deeper understanding, we also comparing mean score of attitude toward behaviour in participants who have a knowledge about consumer right and who don't have knowledge about it. It is found that participants with knowledge have higher average score than participants who do not have knowledge about consumer rights. The mean score for participants who have the knowledge and do not have the knowledge is 42.15 and 31.47 respectively. This result shows that consumer who understand their rights are more likely to have positive attitude toward complaint behavior when receiving candies as change. This result is in line with the idea that cognitive factor as component of attitude which includes belief and knowledge regarding attitude object [15][16]. In this case attitude object is complain behaviour when given candies as change.

The second strongest correlation is shown in association between perceived behavioural control and intention, $r t=.49$. A possible explanation for this result might be that control belief is not associated with perceived power. In this study most participants perceive there are number of inhibiting factors to complain which result in difficulty in adressing a complaint. In addition, most participants also perceive that there are number of facilitating factors in performing a complain (control belief) however, participants do not perceive to have the power over such facilitating factors. According to the result of this study, mean score of facilitating factors is high enough $($ mean $=19.5)$ but the mean score of perceived power control is not high enough (14.6) which suggest that there are facilitating factors that participants belief will support them in addressing a complaint, but are perceived not owned or presence by participants. Therefore, it hamper intention to complain.
The third factor is subjective norm which has the lowest correlation with intention, $\mathrm{rt}=.267$. This result indicate that what subject believe regarding their social referent expect them to do or not do and to what extend they are motivated to comply or not is not associated with intention to complain. The reason behind this is not clear, but it might be caused by the low overall score of normative belief and motivation to comply. According to the result of this study it shows that the mean score of normative belief is 13.86 (out of 30) and the mean score of motivation to comply is 13.73 (out of 30) which suggest that there are no social pressure to address complaint behaviour and participants have low motivation to comply with their social referent expectation, and thus result in low association with intention, in this case, intention to complain

This study provide insight of why people hesitate to complain. According to the result of this study, it is caused by negative attitude toward complain behaviour, nonpresence of facilitating factors to complain, and non supporting normative belief regarding complain behaviour, also low motivation to comply with social referent. With regard to the research method, some limitations need to be acknowledged. Firstly, intrument used in this research were not properly developed, and thus might not under represent behaviour sample in addressing complain when given candies as change. Secondly, sampling method used was not random, and the data collected were not followed normal distribution, and thus the result of this study might not represent the population. Based on that limitation, we urge to take cautios generalization.

\section{CONCLUSION}

This study aims to understand intention to complain of consumer who receive candies as change. Interestingly, even when this situation is violating their rights, consumer is hesitated to complain. According to this study, consumer IS hesitated to complain because most participants $(41.7 \%)$ have low intention to complain. There are significant positive correlations between attitude toward behavior and intention $r t=.646, \hat{p}<.05$ subjective norm and intention, $r t=.267, \hat{p} p<.05$ and perceived behavioural control, and intention, $r t=.490$, $\hat{p}<.05$. These results further support the idea that attitude toward behavior, subjective norm and perceived behavioral control are predictors of Intention.

\section{REFERENCES}

[1] R.G.Folger and R. Cropanzano. Organizational Justice and Human Resource Management"California: Sage Publications, 1998,

[2] T.W. Andreassen. "Antecedents TO Satisfaction WITK Service Recovery" The European Journal of Marketing, vol.34, 2000

[3] S. Butelli. "Consumer complaint behavior (CCB): a literature review. Internet:

http://dspaceunipr.cineca.it/bitstream/1889/1178/1/Butelli\%2520Literature\%2520revi ew.pdf Sept 62007 [Aug. 1, 2017] 
[4] C.C. Margaret. "Perception of Proce Unfairness: Antecedents and Consequences." Journal of Marketing Research. Vol, 46, pp. 187-99, May, 1999

[5] N. Young and S.C.Jang. "Effects of perceived service fairness on emotions, and behavioral intentions in restaurants" European Journal of Marketing, vol. 44, pp. 1233-59, 2010

[6] L.S. Boutaibi. "Consumer Complaint Behavior Anno 2014”. Master Thesis, Erasmus Universiteit Rotterdam, Rotterdam, 2014

[7] C.S. Lin, and C.Chen. "Application of Theory of Planned Behavior on the Study of Workplace Dishonesty" 2010 International Conference on Economics, Business and Management, 2011, PP. 66-69

[8] I. Ajzen. Attitudes, Personality and Behavior. Newyork: Mc-Graw Hill 2005

[9] P.A.M. Van Lange, A.W. Kruglanski, and E.T. Higgins. Handbook of Theories of Social Psychology, London: Sage Publication 2012

[10] M. Fishbein and I. Ajzen. Belief, attitude, intention and behavior: An introduction to theory and research. Reading: Addison -Wesley, 1975

[11] K. Mukhtiar, N, Asmat, M. Arshad, M.A. Ali, H.A.Lodhi, A.Waqas. "Complaint Intentions of Consumers of Pakistan Restaurant Industry."
International Journal of Learning and Development, vol. 3. Pp. 153166,2013

[12] C.C. Chang and Y.C.Chin. " Comparing consumer complaint responses to online and offline environment" Internet Research, vol. 21, pp. 124 137,2011

[13] C. Kim, S. Kim, S. Im, and C. Shin. "The effect of attitude and perception on consumer complaint ontentions." Journal of Consumer Marketing, vol. 20, pp. 352-371, 2003

[14] W. Zhao, M.N. Othman. "”Prediciting and explaining complaint intention and behavior of malaysian consumers: an application of the planned behavior theory." International Marketing in the fast changing world, vol. 21, pp.229-252. 2011

[15] S. Azwar. Sikap Manusia: Teori dan Pengukurannya. Yogyakarta: Liberty, 2012

[16] C. Jansson-Boyd. Consumer Psychology, Berkshire: McGraww-Hill Education, 2010 